\title{
Rituaes e festas Bororo. A construção da imagem do índio como "selvagem" na Comissão Rondon
}

\author{
F ernando de $\mathrm{T}_{\text {acca }}{ }^{1}$ \\ Professor do D epartamento de M ultimeios do Instituto de A rtes - Unicamp
}

\begin{abstract}
RE SUMO : 0 artigo faz uma análise do filme Rituaes efestas Bororo, realizado em 1917 pelo Major Luiz Thomaz Reis nas suas primeiras filmagens como responsável pela Seção deCinematografia eFotografia da Comissão Rondon. A análise centra se na narrativa cinematográfica e sua contraposição com fotogramas publicados no volume I da série Índios do Brasil, assinada por Cândido Mariano da Silva Rondon e publicada em 1946. Para o autor do artigo, o filme faz parte de um conjunto maior de imagens da Comissão Rondon e traduz um momento sígnico indicial da construção da imagem do índio como "selvagem" ou de uma cultura que mantém suas práticas tradicionais. A película é considerada atualmente como um marco na história do filme etnográfico.
\end{abstract}

PALAVRAS-CHAVE: fotografia, filme etnográfico, antropologia, Bororo, Luiz Thomaz Reis.

\section{Introdução}

Pretendo neste artigo analisar o filme Rituaes e festas Bororo (1917), de Luiz Thomaz Reis, de expressiva importância para a história do filme etnográfico, pelo seu pioneirismo e pela sua original proposta narrativa. Antes de entrar na análise fílmica e nas relações imagéticas relacionadas ao tema, apresento inicialmente um resumo das atividades da Comissão Rondon, na qual Reis participou ativamente como cinegrafista e fotógrafo, sob o comando do Marechal Rondon. 
Cândido Mariano da Silva Rondon, recém-saído da academia militar como oficial-engenheiro, participou como ajudante do Major Gomes Carneiro nas primeiras comissões de linhas telegráficas formadas a partir de 1889. Com a anuência de Gomes Carneiro e, principalmente de Benjamim Constant, então Ministro da Guerra e um dos líderes da implantação da República, o então jovem capitão assumiu desde logo a chefia da Comissão Construtora de Linhas Telegráphicas do Araguaia. Rondon participou ativamente das ações que levaram à queda da monarquia e foi influenciado diretamente por Benjamim Constant na sua entrada para a doutrina positivista, cristalizada no Brasil através da Igreja Positivista. Sua primeira ação comandando a linha telegráfica Cuiabá-A raguaia construiu em apenas 13 meses $524 \mathrm{~km}$ de linhas telegráficas. Na sua volta ao Rio de Janeiro, em 1891, assume por pouco tempo a cadeira de Astronomia na Escola Militar da Praia Vermelha e aceita 0 convite de $\mathrm{G}$ omes Carneiro para chefiar os destacamentos militares ao longo da expansão das linhas telegráficas de Mato $\mathrm{G}$ rosso e do Amazonas, construindo as estações entre Cuiabá e Porto Velho. Assume também a Comissão Construtora de Linhas Telegráphicas no Estado de Matto-Grosso (de Cuiabá a Corumbá, prolongando-se até as fronteiras de Paraguai e Bolívia, entre 1900 e 1906). Estamos considerando em nossa análise a participação de Rondon nas várias comissões telegráficas, no processo de formação, implantação e ação do SPI (Serviço de Proteção ao Índio) e, por último, na Inspetoria de Fronteiras. Nas palavras de Rondon há uma relação direta entre os vários órgãos de que participou, os quais não podem ser analisados separadamente:

Convém salientar que a Inspeção de Fronteiras pôde realizar o programa que organizei por ser ela filha dileta da antiga Comissão Telegráfica, ou Comissão Rondon, como já o havia sido o Serviço de Proteção ao Índio. (Viveiros, 1958: 573)

O utra grande empreitada de Rondon foi na chefia da Comissão de Linhas Telegráphicas Estratégicas de Matto-Grosso ao Amazonas, encerrada em 1916, a qual o colocou frente a frente no sertão a vários 
Revista de Antropologia, São Paulo, USP, 2002, v. 45 no 1.

grupos indígenas de pouco contato com a "civilização", levando-o a criar o Serviço de Proteção ao Índio, em 1910. Essas expedições, segundo ele, "de maior vulto e larga projeção em outros setores de atividades e progresso, aí compreendido o grave 'Problema do Índio', que tivemos de resolver, ao penetrarmos nas zonas de sertão em que nossos índios viviam livres do contato com os civilizados, tantas vezes prejudiciais a sua paz e a sua independência" (Rondon, 1953b: 3). Chamado inicialmente de Serviço de Proteção ao Índio e Localização do Trabalhador Nacional, esse órgão governamental esteve ligado ao Ministério da Agricultura e já trazia a idéia de integração das populações indígenas ao processo produtivo nacional. Influenciado fortemente pelo positivismo, Rondon deu uma característica humanística ao SPI.

O espírito científico das grandes expedições do século passado e do início deste influenciou Rondon a levar junto botânicos, zoólogos e outros cientistas para fazer levantamentos da fauna e da flora. 0 levantamento topográfico e geográfico foi feito pelo próprio Rondon e seus ajudantes, e ele também fez levantamentos etnográficos da cultura material de alguns grupos indígenas e medições antropométricas dessas populações. Todos esses trabalhos foram publicados com 0 título de Publicaọões da C omissão Rondon em pequenos e grandes volumes no total de cem publicações. As diversas comissões chefiadas por ele ficaram conhecidas mais tarde simplesmente como "Comissão Rondon", e sua atuação na Inspetoria de Fronteiras está inserida nesse contexto na nossa análise. $\mathrm{O}$ mito rondoniano foi sacramentado por uma ampla produção biográfica².

Em 1912, Rondon cria a Secção de Cinematographia e Photographia sob a responsabilidade do então tenente Thomaz Luiz Reis. O Major Thomaz Reis, como ficou conhecido mais tarde, viaja para a Europa para comprar equipamentos e começa seus primeiros registros em 1914. Reis será o principal fotógrafo e cineasta da Comissão Rondon. Antes de 1912 Rondon contratou os serviços de uma casa comercial do Rio de Janeiro, o que não deu certo pelas distâncias percorridas e também 
pela falta de experiência dos fotógrafos no trabalho de campo. Reis não será 0 único fotógrafo das diversas expedições, podemos citar pelo menos alguns como José Louro, Dr. Benjamin Rondon e Cel. Joaquim Rondon, Charlotte Rosenbaum e Exp. Carlos Lako.

A criação de uma seção especializada em documentação em material fotossensível foi uma ação inovadora para os padrões da época, necessitando altos investimentos e apropriação de uma tecnologia especializada inexistente no país, principalmente se levarmos em conta que 0 uso desse material se daria em péssimas condições ambientais, no sentido das dificuldades de transporte e também da alta umidade. A documentação imagética foi considerada como outras atuações científicas da Comissão, apresentando relatórios e publicações como a E x pedição ao rio Ronuro, publicação no 90 , relatada pelo capitão Vicente de Paulo Teixeira da Fonseca Vasconcelos, em 1945. Nesse relatório cita as duas câmaras de cinema pertencentes à Comissão operadas por ele: uma Williamson de 30 metros e uma Debrie Studio de 120 metros que, segundo ele, utilizava para os "estudos mais importantes". Reis demonstra conhecimentos técnicos avançados de cinema, entretanto, não freqüentava o próprio meio cinematográfico, pois não foram encontrados dados demonstrativos dessa inserção.

A importância que Rondon atribuía aos registros imagéticos como forma de convencimento pode ser avaliada pelo relatório que a Comissão encaminhou ao Presidente da República, Artur Bernardes, em 1922. São dois volumes contendo mais de quatrocentas fotografias da construção das linhas telegráficas, aspectos de vários povos indígenas e tomadas de cenas do sertão. D epois de vários insucessos utilizando os serviços de um importante estabelecimento comercial de fotografia do Rio de Janeiro, a Casa Muso, Rondon aceitou a proposta de um jovem oficial (também engenheiro) que o acompanhava, então tenente Luís Thomaz Reis, para formar o Serviço Fotográfico e Cinematográfico da Comissão Rondon, em 1912. Nesses relatórios, Rondon enfatizava os trabalhos das linhas telegráficas mas não deixava de mencionar os contatos com 
Revista de Antro pologia, São Paulo, USP, 2002, v. 45 nํㅜ‥

os grupos indígenas. Se a persuasão atingia as autoridades através das fotografias, as apresentações dos filmes e os artigos publicados nos principais jornais do país visavam principalmente outro grupo formador de opinião, a elite urbana sedenta de imagens e informações sobre 0 sertão brasileiro, e Rondon alimentava o espírito nacionalista construindo etnografias de um ponto de vista estratégico. Antônio Carlos de Souza Lima enfatiza a composição militar da Comissão, que usa aproximação expedicionária de um "fazer ciência":

Claro está que este contingente específico de engenheiros-militares era uma das facções do Exército o qual, na medida de seu crescimento, sofreria alterações substantivas ao longo do período. Um trabalho mais acurado, voltado para o Exército menos como instituição sem fissuras internas, poderia pensar o jogo faccional de modo a situar o poder real desse grupo de interesses em relação aos demais gnupos existentes. Estafacção comporia o corpo principal daComissão de Linhas Telegráficas e Estratégicas do Mato G rosso ao Amazonas (CLTEMGA). É importante destacar que o termo estratécicas, que confere seu sentido militar e o recoloca dentro das questões mais gerais de defesa do território, povoamento, e de guarda das fronteiras, acha-se freqüentemente omitido na literatura encomiástica que trata do assunto, aproveitando-se a polissemia do termo œmissão, empregado à época também para designar os empreendimentos intelectuais de penetração e conhecimento do território, isto é, as œmissões científicas. (Souza Lima, 1992: 162, grifos do autor)

O material fotográfico mais consistente foi publicado em três volumes nos anos de 1946, 1953, com o título de Índios do Brasil, assinado pelo próprio Rondon. G rande parte da documentação fotográfica dos grupos indígenas da Amazônia foi feita quando Rondon estava na chefia da Inspetoria de Fronteiras, entre 1934 e 1938. Rondon também utilizava como estratégia de mark eting vários álbuns fotográficos ${ }^{3}$ e os enviava na forma de relatórios aos seus superiores, como foi dito acima. Rondon tinha forte apoio dos órgãos de imprensa, nos quais sempre publicou artigos sobre seus trabalhos, e completando seu mark eting apresentava os filmes feitos pelo Major Thomaz Reis em apresentações públicas, seguidas de conferências. Um dos poucos álbuns que pudemos examinar no Forte de Copacabana, A Campanha do Paraná. 1924-1925, com 211 
fotografias do então capitão Thomaz Reis, mostra aspectos tomados durante a ação das Forças em O perações de Guerra contra os rebeldes da Coluna Prestes, nos estados do Paraná e Santa Catarina, sob o comando do G eneral de Divisão Cândido Mariano da Silva Rondon. O álbum foi impresso na Itália, sendo os clichês feitos na empresa Cliché Rápido, Milão, Via Melzo, 13 e impresso na gráfica E speria, Milão, via Paolo Sarpi, 44. Tal fato demonstra o grau de sofisticação do mark eting rondoniano, transferindo sua seção fotográfica e cinematográfica das linhas do telégrafo para uma operação de guerra, para depois retornar ao sertão, e mais, imprimindo seus álbuns no exterior. Infelizmente, as imagens de vários álbuns no Forte Copacabana estavam desaparecendo em virtude da falta de preservação, sendo várias delas irrecuperáveis. Osfilmes eas fotografias da Comissão eram exibidos em grandes audiências públicas que formavam o imaginário das populações das cidades sobre o sertão e sobre os povos indígenas.

Antônio Carlos de Souza Lima é o autor que mais recentemente debruçou-se na temática rondoniana e na gênese do indigenismo no Brasil, entretanto, tece inicialmente na sua vasta obra somente um vago comentário sobre a produção imagética da Comissão Rondon, circunscrevendo-a a um valor menor ou como ele diz a um subproduto. Souza Lima ressalta, como o principal exemplo, "o material fotográfico, que ilustra livros e publicações do Serviço e mais tarde também do Conselho Nacional de Proteção aos Índios" (1992: 112), e cita os três volumes de Índios do Brasil, como um processo de escolha de alguns grupos étnicos para realizar uma atribuição de indianidade que, dessa forma, esquecem outros grupos sob ação do SPI:

D e qualquer forma, compunha-se um acervo a retratar o índio genérico, numa unificação do heterogêneo produzida pelo olhar exógeno, pela ação do poder tutelar que os agrupa. Conquanto declarados os povos, com abundância de retratos específicos ( como se a intenção fôra fotografar tipos humanos somaticamente distintos), as fotos demonstram sobretudo as acōes do Servigo, servindo para enaltecê-lo, tal como podem servir para estudálo. (Souza Lima, 1992b: 113, grifos do autor) 
Revista de Antropologia, São Paulo, USP, 2002, v. 45 no 1.

Souza Lima centra-se nas imagens publicadas nos álbuns citados como fotografias, quando são em sua grande maioria fotogramas seqüenciados dos vários filmes da Comissão. A imagética rondoniana é analisada em minha pesquisa como um produto em si mesmo, por meio de um desenvolvimento semiótico da imagem fotográfica (D ubois, 1998) que escapou das esferas específicas de atuação de Rondon, para persistir como uma permanência retiniana até os dias de hoje pela sua dinâmica visual interna; uma imagem-conceito (Flusser, 1985). A intenção deste artigo é abordar especificamente a Comissão Rondon pela sua produção visual (particularmente as imagens técnicas) com a intenção de compreender as narrativas fílmicas e fotográficas e as relações sobrepostas de imagens e textos. A ação oficial que Souza Lima identifica como a de retratar o índio genérico, no nosso caso, trata-se da construção genérica de uma imagem-conceito do índio. É importante notar, mesmo observando que Souza Lima não considera as imagens em si como documentos de sua pesquisa inicial, que ele aludiu a sua importância como tal e irá incoporá-las em outros artigos (1992 e 1995) de forma orgânica e significativa, e não meramente ilustrativa ao seu pensamento.

O primeiro volume da publicação Índios do Brasil contém fotografias dos índios do Mato $\mathrm{G}$ rosso; o segundo volume abrange os rios A raguaia e Oiapoque, e as cabeceiras do rio Xingu com seus vales, inclusive seu formador, 0 rio Ronuro; e 0 terceiro volume abrange 0 vale do Rio Trombetas, e também Jari, Negro e Branco, na Amazônia. As expedições dentro da selva abrindo picadas e fazendo levantamentos geográficos foram penosas e muitas imagens fotográficas e cinematográficas foram perdidas em travessias de rios perigosos ou mesmo na revelação dos negativos, quando os insetos devoravam a película, principalmente de cinema, como diz Thomaz Reis:

Depois de seis meses de serviço, sob minha observação pessoal, pois que era a primeira vez que fazia isso no sertão, tendo por felicidade estudado a "emulsão" e o tempo de sua efficiência em zonas quentes e humidas, o que 
me levou a preparar aparelhos de madeira especiaes para revelar os films no local, foi então obtido com vantagem o film conhecido por Sertões do M atogrosso, exhibido em 1915 no Rio de Janeiro e depois, em todo o Brasil. (Magalhães, 1930: 328)

Este filme infelizmente não foi encontrado inteiro, sendo somente recuperados alguns de seus fragmentos. A documentação fotográfica da Comissão Rondon sobre os povos indígenas apresenta dois momentos contraditórios. Apesar de procurar registrar etnograficamente os costumes e a cultura material, como mostra a seqüência de confecção de máscaras de uma festa entre os Uanâna do rio Içana, alto do rio Negro, desde 0 momento de retirada da casca do Tururi, para posterior pintura, e finalmente até mostrar o próprio ritual em 53 fotogramas (Rondon, 1946, vol. III: 158-89), as seqüências fotográficas e cinematográficas procuram também mostrar um índio genérico, permissível ao contato com os brancos, autodenominados "civilizados".

Cinco filmes dos quais temos conhecimento pelas anotações de campo e cruzamento de outras informações da filmografia da Comissão Rondon não foram encontrados até hoje:

- D e Santa Cruz (1917);

- E x pedição R oosevelt ao M atto-G rosso (1915);

- Indústria da borracha em M inas G erais e no A mazonas (1917);

- Inspeccão no N ordeste (1922);

- 0 perações de guerra (1926).

O s filmes encontrados e que estão preservados na Cinemateca Brasileira são os seguintes:

- Rondonia (1912), de Edgar Roquete Pinto, 13 min.

- Rituaes e festas Bororo (1917), de Thomaz Reis, 20 min.

- A 0 redor do Brasil - aspectos do interior e das fronteiras brasileiras, (1932), de Thomaz Reis que inclui:

- Ronuro, selvas do X ingu, 15 min.

- O s Carajás, 10 min. 
Revista de Antropologia, São Paulo, USP, 2002, v. 45 no 1.

- V iagem ao Roraimã (1927), de Thomaz Reis, 10 min.

- Parimã, fronteiras do Brasil (1927), de Thomaz Reis, 24 min.

- Inspetorias de fronteiras (1938), de Thomaz Reis, $80 \mathrm{~min}$.

A imagética do SPI pode ser dividia em dois momentos distintos. Em um primeiro momento, a produção fotográfica e cinematográfica da Comissão Rondon se confunde com a produção do próprio SPI. É um total de 1.200 imagens fotográficas e os filmes citados acima. No segundo momento, que podemos chamar de período de sistematização da documentação fotográfica e cinematográfica, com características claras de documentação etnográfica, acontece por meio da criação da Seção de Estudos do SPI, em 1942, e da qual faziam parte Harald Schultz, Heinz Foerthman, Nilo Veloso e, em seguida, D arcy Ribeiro. Esse material ainda não explorado devidamente contém um arquivo precioso de atividades culturais de grupos já extintos e de grupos indígenas atuais. Com um volume de imagens muito maior do que 0 anterior e organizado com critérios objetivos claramente indexados, no qual é possível acompanhar a documentação fotográfica com detalhes tanto de uma construção de uma casa xinguana como as diversas fases do ritual funerário Bororo, esse arquivo é um acervo etnográfico valioso e resultado de preservação e conservação, esforços pessoais, de alguns funcionários abnegados do Museu do Índio4.

\section{Análise fílmica}

A intenção deste artigo é abordar o filme Rituaes e festas Bororo, de expressiva importância para a história do filme etnográfico, e analisar seu conteúdo, através de metodologia específica de aproximação com a narrativa cinematográfica, pela intertextualidade com narrativas publicadas pertinentes ao tema. Pretendo compreender o processo de produção de sentido fílmico sobrepondo informações publicadas em relatos escritos, principalmente na narrativa publicada posteriormente aos fotogramas intermediados por algumas fotografias no livro Índios 
do Brasil, assinadas por Cândido Mariano da Silva Rondon. A análise que apresento faz parte de uma tríade sígnica formada pela construção da imagem do índio como "selvagem", "pacificado" e "integrado/ civilizado" (Tacca, 1998).

Realizado pela Comissão Rondon, em 1917, Rituaes e festas Bororo foi filmado e montado pelo Major Thomaz Reis. Nossa análise parte da decupagem detalhada das sequiências cinematográficas e das tomadas que engendram a montagem do filme. A metodologia de aproximação com o produto fílmico aprofunda o detalhamento crítico e a compreensão da construção de sentido na captação das imagens em campo e as suas relações com a montagem ${ }^{5}$. 0 filme pode ser dividido em duas partes distintas. A primeira parte, que trata de alguns aspectos da vida cotidiana e da cultura material, como a pesca, a cerâmica, a tecelagem, está diretamente implicada na segunda parte do filme: 0 ritual funerário propriamente dito ${ }^{6}$.

Antes de aprofundarmos a análise do filme é importante esclarecer que os índios Bororo mantinham uma relação intensa com missionários salesianos, que chegaram ao Brasil em 1883, abrindo suas missões em Mato G rosso já no ano seguinte. Sylvia Caiuby Novaes $(1993)^{7}$ tece profunda análise da construção da identidade Bororo: o "jogo de espelhos" propicia-lhe a metáfora especular da construção de uma autoimagem, a partir do outro. Novaes vai construindo uma complexa teia de auto-imagens existentes como um "caleidoscópio", a partir dos vários agentes que entram em contato com os Bororo, inclusive índios X avante, seus vizinhos.

Para os que vêem o filme de Reis pela primeira vez, a impressão de que aqueles indígenas estão completamente isolados e com quase nenhum contato com os brancos pode ficar marcada pela ênfase somente nos processos ritualísticos e nas práticas culturais, como 0 artesanato e a pesca. Em nenhuma passagem visual nem tampouco nas cartelas, Reis explicita a presença dos salesianos. Já em 1890, Rondon como jovem tenente, quando ainda era ajudante do então Major Gomes 
Carneiro, relata os difíceis contatos que se estabeleceram com os Bororo quando abriam picadas na selva e eram hostilizados pelos índios:

Naquelaépoca os Borôro eram amontados, isto é, completamente selvagens e, portanto, inimigos dos civilizados, aos quais hostilizavam, em represália às persiguições que lhes eram feitas por êstes, desde a época da descoberta do continente ( Os Bandeirantes). (Rondon, 1946: 223, grifo do autor) ${ }^{8}$

Magalhães continua a exemplicar esse primeiro contato dos índios Bororo com a Comissão e as decodificações de signos no contato interétnico quando diz que:

Os índios espreitavam os mínimos movimentos dos chefes e das turmas de construção e muitas vêzes os dois engenheiros-militares se curvaram a ultimatos dos Borôro, desviando o rumo de certos alinhamentos, onde os índios fincavam suas flechas de intimição, quando percebiam, pela direção do traçado, que o pique iria incidir em uma de suas aldeias (... ). Assim, pela bondade e pela tolerância, enchendo de brindes os lugares freqüentados pelos selvícolas, acabaram os Borôro por se arriscar a entrar em contato com os acampamentos da Comissão e confratenizar com os civilizados. (Idem)

Posteriormente os contatos na selva e a aproximação com os serviços da Comissão levariam Rondon a usar os préstimos dos índios, levandoos a trabalhar nos serviços mais difíceis e fazendo "substituições" pelo fato de a Comissão contar com poucos recursos e falta de pessoal:

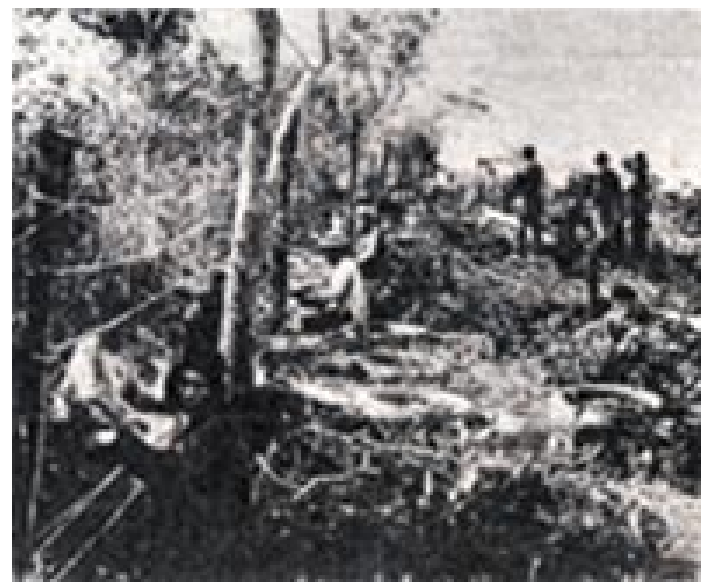


Os Borôrosprestaram seu concurso para a construcção das linhas telegráficas do Sul do Estado. D urante longo período, no qual a difficuldade de recursos pecuniarios e de pessoal para o contigente militar ameaçava a suspensão dos trabalhos, o G eneral Rondon obteve turmas diárias de 100 a 150 Borôros para os serviços mais penosos através de pantanaes. No decorrer do dia, quando o sol attingia á altura maxima, os Borôros procuravam esconder-se na mata, para se defenderem do calor exhaustivo. Conta-se então que só 0 $G$ eneral obtinha delles o trabalho nessas horas de sol quente, fazendo-os rir e retomar o serviço, falando-lhes em Borôro, em termos que os alegravam e convenciam. (Magalhães, 1942: 324)

E completa de forma apoteótica sua visão do contato com os grupos indígenas enfatizando o roteiro positivista do progresso na nação, através do sonhado roteiro da passagem da condição de "selvagem" para a condição de "civilizado", quando afirma em outro momento:

Os dois grandes militares haviam assim estabelecido as bases verdadeiramente sólidas sôbre as quais as gerações futuras e as futuras organizações dos Serviços de Proteção aos Índios deviam construir a obra humanitária da aproximação e incorporação do Índio à Civilização, tão belamente preconizadas pelo grande estadista brasileiro José Bonifácio de Andrada e Silva. (Rondon, 1946: 224)

Em um artigo publicado em 1942, na revista A merica Indigena, continuando a citar José Bonifácio, Rondon enfatiza os cinco mandamentos criados por ele para propiciar "os meios de que se deve lançar mão para a pronta e sucessiva civilização dos índios" e, entre eles, o quinto mandamento que propõe incentivar a miscigenação dos povos indígenas com brancos e mulatos ${ }^{9}$.

É possível verificar que antes mesmo do estabelecimento das missões salesianas entre os Bororo, a própria Comissão havia feito contato amistoso com os mesmos, mas tanto no livro Índios do Brasil quanto no filme Rituaes e festas Bororo não é citada a presença missionária, apesar de aparecer imagens de uma usina de cana-de-açúcar (244-7). Novaes lembra que são os missionários que introduzem o trabalho agrícola e, entre outras culturas, a cana-de-açúcar (1993: 145), e cita a fonte original que comprova que a presença missionária na área era atuante 
em 1906, quando índios Bororo do rio São Lourenço entraram em contato com os missionários (: 155). Assim, as cenas do trabalho na usina de cana-de-açúcar que aparecem no livro como fotogramas faziam parte inicialmente do material bruto do filme.

Os missionários salesianos só vão aparecer e ser celebrados como integradores do índio na vida "civilizada" em cenas realizadas no Alto rio Negro, no final na década de 1930 em filme da Inspetoria de Fronteiras. Pela descrição que faz Novaes, a relação entre Bororo e salesianos era tão intensa que estes muitas vezes eram chamados para tentar resolver atritos, mesmo fora de sua área de atuação, que convergiam para seus interesses catequéticos de ampla dominação espiritual e moral:

Ao se colocarem na defesa dos Bororo, os salesianos acabam também por minar as suas iniciativas, e colocá-los na sua total dependência. A relação de dependência era, em todos os sentidos, estratégica para os missionários. (Novaes, 1993: 158)

Será que interessava mostrar um índio sendo aculturado e estando dependente de religiosos em um programa fílmico apresentado em Nova Iorque em 1918?

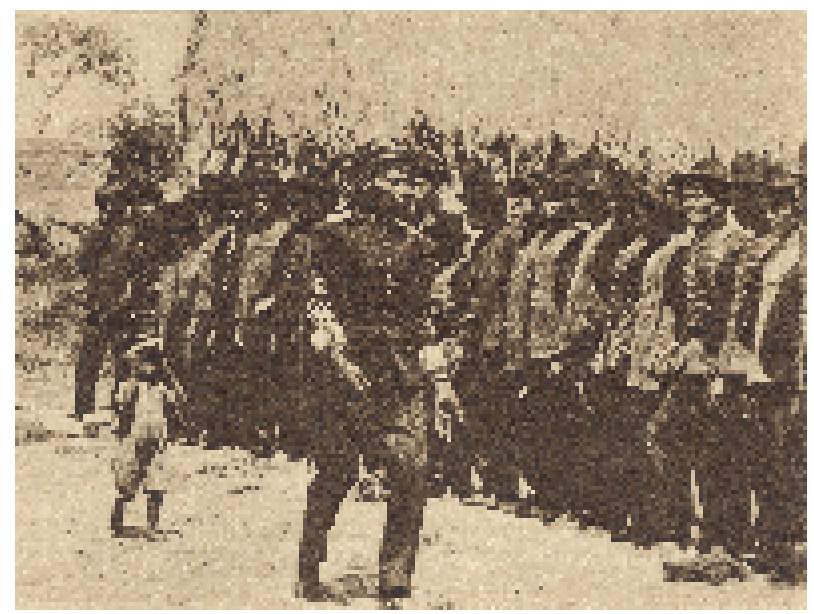



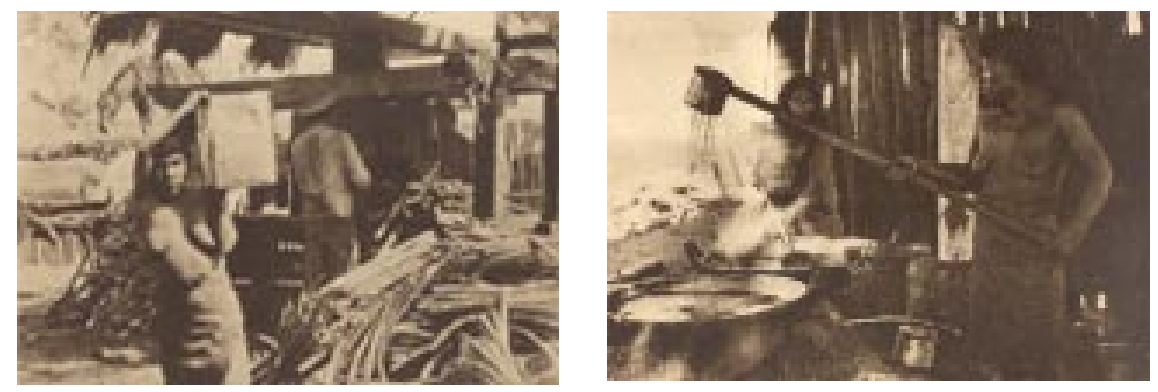

O então jovem capitão e cineasta Luiz Thomaz Reis viajou para os Estados Unidos em 1918, patrocinado pela N ational G eographic Society, exibindo no $\mathrm{C}$ arneggie $\mathrm{H}$ all de Nova Iorque a película W ilderness (chamada no Brasil D e Santa C ruz), por ocasião de uma palestra proferida por Theodore Roosevelt. Rituaes e festas Bororo fazia parte do programa W ilderness, juntamente com cenas do Pantanal de caçadas de onças e os Saltos Iguassu. Rondon guiou Roosevelt em uma expedição científica pelas selvas do Mato Grosso entre 11/ 12/ 1913 a 07/ 05/ 1914. A expedição foi acompanhada por Reis, que em 1914 dirige o filme E x pedição Roosevelt a M ato G rosso. Segundo o próprio cineasta, esse filme ficou incompleto mas foi exibido com o título Ex xedição Roosevelt em 1915 durante conferências de Rondon no Teatro Phenix, no Rio de Janeiro. A viagem foi nomeada pelo governo brasileiro de Expedição Científica Roosevelt-Rondon.

$\mathrm{O}$ relato de viagem publicado por T. Roosevelt traz passagens que demonstram essa procura do exótico e do inexplorado. 0 título da edição em inglês já demonstra isso, Through the Brazilian W ilderness, 0 título em português segue a mesma lógica: $\mathrm{N}$ as selvas do Brasil. É comum em seus relatos Roosevelt afirmar que estava "caçando" por interesse científico ${ }^{10}$ mas na expedição havia o trabalho de empalhadores para os espécimes que lhe interessava mais para as coleções dos museus norte-americanos: "Q uando parti dos Estados Unidos, tencionava fazer inicialmente uma expedição dedicada ao estudo de mamíferos e aves 
Revista de Antropologia, São Paulo, USP, 2002, v. 45 no 1.

para o Museu Americano de História Natural, de Nova Iorque" (Prefácio). Assim, o índio que aparece nesse roteiro da expedição científica é uma mera conseqüência de exploração de um mundo desconhecido.

O lado selvagem dos índios brasileiros é relatado no seu encontro com índios Nhambiquara no alto do rio Tapajós, local conhecido por Juruena. Em uma passagem desse encontro com os Nhambiquara afirma que "são todos, homens, mulheres, rapazes e mocinhas, tão ingênuos e ignorantes como animais domésticos" (Roosevelt, 1942: 204). São apresentadas algumas fotografias em que aparecem ao lado de Rondon, montados em seus cavalos, os índios nus "muito mansos e sociáveis"11. Uma fotografia chama a atenção pela legenda que tenta relacionar um indío, uma mulher e uma criança com o mito de origem do cristianismo, diz a legenda: A dão e E va (: 211).

$\mathrm{Na}$ "Apresentação" da primeira edição brasileira em 1942, o então ministro da agricultura Apolonio Salles corrobora para esse entendimento da expedição que aconteceu mais de trinta anos antes, diz ele:

O interêsse científico e, sobretudo, o sabor exquisito da aventura em terra estranha, levaram o estadista ilustre a transformar-se em uma nova sorte de indigenista, à cata de exemplares zoológicos, explorador da geografia de zonas ainda não conquistadas pela civilização, observador inteligente da terra e do homem queiria conhecer, os quais analisaria com carinho ejusteza. (Roosevelt, 1942: VII)

O excêntrico ritual funerário perderia seu impacto "selvagem" e sua originalidade caso se mostrasse a outra face dos Bororo em processo de aculturação, e o componente inóspito da viagem do ex-presidente norte-americano ficaria desinteressante, já que até mesmo exploraram um novo rio que acabou sendo batizado com seu nome (antigo rio da Dúvida). A omissão dos salesianos na edição do filme toma um rumo muito interessante quando constata-se que é exatamente o ritual funerário um dos pontos de maior assombro dos mesmos com as práticas culturais desse povo e um de seus focos de concentração da ação missionária, 
chegando até mesmo a produzir interferências na dimensão temporal, quando propõem um tempo maior entre processos de culto ao morto, desenterrando e descarnando o cadáver para ornamentá-lo, fazendo essa interferência com justificativas assépticas, como diz Novaes:

Além das inúmeras disputas que os missionários travavam com os bari, um dos costumes com que os salesianos mais se debateram foi o funeral Bororo (... ). D e todas as mudanças que os missionários vão tentando introduzir nas questões funerárias, esta parece ser a única que definitivamente foi incorporada pelos Bororo, que hoje esperam cerca de dois meses, a partir da morte de um indivíduo, para ornamentar os seus ossos. (1993: 160)

Se, por um lado, os salesianos se consideravam vitoriosos na interferência do ritual, a autora diz que os Bororo, por outro, aceitaram pois passaram a ter mais tempo para se dedicar aos inúmeros rituais permitindo, dessa forma, afastar-se das imposições de trabalho, escola, cerimônias cristãs, etc., atividades esquecidas neste processo ritualístico, pois como diz Novaes:

O funeral Bororo era visto pelos salesianos como uma verdadeira cerimônia diabólica, um culto ao horror (... ) . Combater as práticas funerárias dos Bororo implicava não apenas coibir todos aqueles rituais, mas, fundamentalmente, fazer com que índios passassem a enterrar seus mortos em cemitérios cristãos. (: 161)

De pontos de vista diametralmente opostos, a Comissão Rondon e Missão Salesiana produzem uma imagem dicotômica do índio Bororo, entre 0 selvagem e 0 civilizado, que se tenta construir ou se manipular no começo do século. Novaes cita trecho no qual no ano de 1908, durante as comemorações do centenário da passagem de D. João VI pelo Brasil, foi realizada uma grande exposição e o inspetor dos salesianos

teve a idéia de enviar os meninos Bororo, participantes da banda de música, da colônia do Sagrado Coração de Jesus, a se apresentarem no Rio de Janeiro. O sjovens foram ensaiados pelo alfaiate chefe do colégio de Cuiabá, que era também um bom maestro de música. Receberam uniformes e foram dispensados dos trabalhos agrícolas. Toda a viagem foi custeada pelo governo. (Novaes, 1993: 169) 
Revista de Antropologia, São Paulo, USP, 2002, v. 45 noํ 1.

Entretanto, citando Baudrillard, quando distingue simulação de representação, diz ela que "em determinados momentos desta relação, aquilo que é representação para um é vivido como simulacro para outro, e vice-versa". Em seguida passa a analisar eventos que comprovam sua tese, principalmente a introdução da cruz em uma praça central da aldeia Bororo, em lugar da tradicional casa dos homens, destruída pelos próprios Bororo, influenciados pelo maniqueísmo imposto pelos missionários de ser lá o lugar do "demônio", e a complexidade da absorção dos signos tornando-se seu próprio simulacro, "um referente desreferencializado".

A cruz permanece no local onde foi instalada, sua presença é visível e de alguma forma os valores a que ela remete foram sendo gradativamente incorporados. Não da dimensão ou do mesmo modo do que os missionários supunham e, muito menos, em detrimento à realidade anterior. A casa dos homens foi reconstruída pelos Bororo, longe das vistas dos padres; seus rituais e, fundamentalmente os funerais, que tanto horrorizavam os salesianos, continuaram sendo realizados. (: 178)

O que leva o mesmo governo a patrocinar a viagem de Reis para os Estados Unidos da América dez anos depois levando uma outra imagem do Bororo, uma imagem "selvagem" e "primitiva"? Sem dúvida, diferentes projetos ideológicos e claramente uma manipulação em via dupla da imagem do índio para justificar atos, fatos, valores morais e também angariar recursos, públicos e privados. As fotos apresentadas pela autora encontradas nos arquivos da Inspetoria Salesiana de São Paulo, datadas dessa época (começo do século), reforçam uma tentativa de mostrar somente um lado da relação, e essa parcialidade seria para afastar a idéia de que os Bororo ainda viviam uma "vida nômade e selvagem". As fotografias mostram índios no trabalho de marcenaria, segurando uma bandeira nacional, uniformizados com estética militar; no campo, com enxadas; e em uma das mais impressionantes imagens aparecem cinco índias vestidas com o mesmo tipo de estampa e mesmo tipo de vestido, que cobre todo o seu corpo, retratadas com um tear na frente de cada uma delas; como uma introdução à Revolução Industrial, e entre elas 
uma freira entrelaça suas próprias mãos com um olhar angelical para a câmara (Novaes, 1993: 189). O u, como a autora afirma,

Nestas fotos aparecem, "objetivados", os resultados deste trabalho missionário. São cerca de cem fotos, com temas muito recorrentes, que procuram tornar visível as possibilidades do método salesiano. (: 185)

As transformações da vida e do comportamento dos Bororo podiam ser vistas e divulgadas para um olhar distante dos grandes centros ou da Europa para comprovar também, dessa forma, um simulacro, pois, como afirma Novaes em várias passagens, os Bororo nunca deixaram de realizar seus rituais funerários, até mesmo desenterrando seus mortos dos cemitérios cristãos.

Para quem essa imagem estava sendo produzida? Certamente não era para os próprios Bororo daquela época mas para olhares distantes comprobatórios que se deixavam seduzir pela idéia da catequização dos índios e de sua conversão aos valores cristãos, portanto rebatidos como os valores de uma sociedade civilizada. A descrição de uma viagem para angariar fundos feita por D om Malan, em 1917, que envolvia finos colégios de São Paulo, jornais paulistanos e até associações de mulheres operárias, essas virtudes de seres "obedientes, submissos, trabalhadores e industriosos, já em meio caminho da civilização", conforme citação do Boletim Salesiano, leva Novaes a dizer que essa viagem tinha os Bororo como "cartão de visitas do trabalho missionário" e assim este poderia estender seus trabalhos de conversão para outros grupos étnicos. Se, de um lado, Reis procura o mito de origem ou o primeiro brasileiro na forma como eles viviam nos "tempos do descobrimento" para afirmar umaidentidade nacional, os salesianos procuravam, de outro, sua própria auto-afirmação dogmática.

Voltando ao filme: toda a captação das imagens transcorreu durante um ritual funerário Bororo, que é marcado por momentos de danças, cantos e uma profunda interação entre todos os indivíduos. A idéia de ser Bororo, de encontro com uma identidade cultural, é integralizada no processo de um ritual funerário. 0 filme condensa esta prática de 
uma forma simplista, reduzindo sua dimensão temporal. Se um ritual funerário pode durar meses, o filme não nos permite nem mesmo perceber uma passagem diária. Tudo parece acontecer de forma linear, constante e, até mesmo, em um só dia. Em nenhum momento do filme a dimensão temporal do ritual é dada a perceber ao espectador. Só no começo é dito em uma cartela que a pesca dura alguns dias. A pesca, entretanto, já faz parte da preparação do ritual, que fica claro quando o filme, através de uma cartela e de uma seqüência, mostra-nos a fartura de alimentos, principalmente peixes, no meio de uma série de danças.

Se é possível dividir metodologicamente o filme em dois momentos - a preparação do ritual e o ritual propriamente dito - , é também possível perceber diferenças na relação da câmara com a ação desenvolvida à sua frente. No primeiro instante, a câmara dirige, em parte, a ação dos indivíduos e escolhe-se o lugar para filmar a ação e o sujeito a ser filmado. A presença da câmara é muitas vezes anunciada pela inquietação dos sujeitos filmados que constantemente repetem olhares para o extraquadro antes de olhar diretamente para a câmara, estabelecendo uma pró-filmia. O u mesmo, como no caso da pesca, a ação de morder a cabeça do peixe é feita para a câmara.
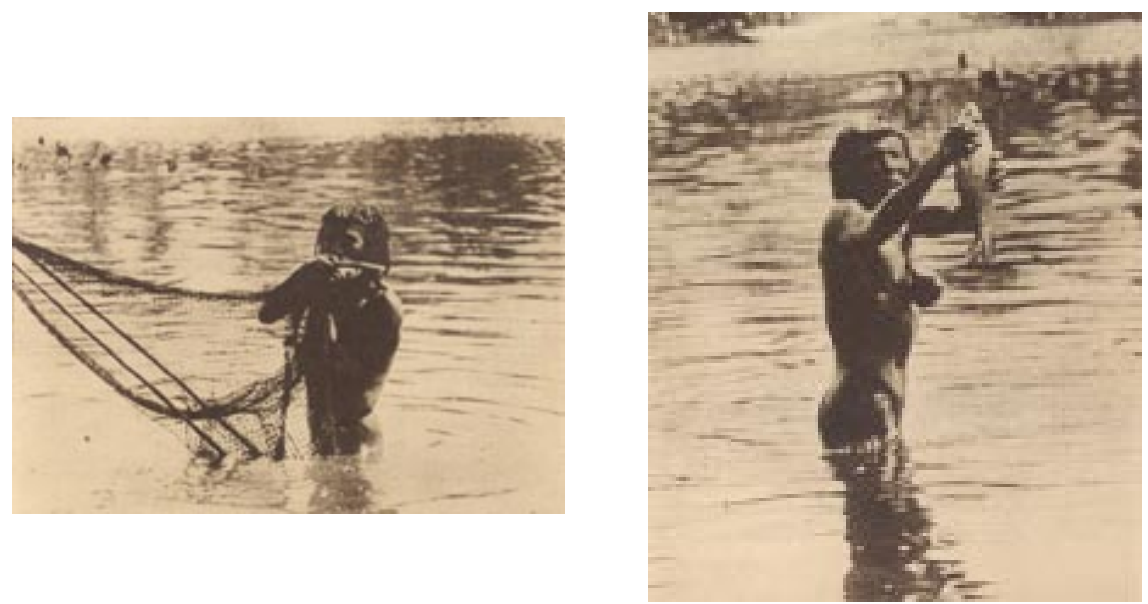
Por outro lado, durante as danças do ritual, a posição e o ângulo de tomada da câmara são pensados em termos de uma "neutralidade" ou "imparcialidade" na medida em que procura não se "interferir" nas ações. Em todos os movimentos de dança e ações do ritual, a câmara se coloca de maneira não agressiva, mantendo uma certa distância dos acontecimentos. O s próprios participantes do ritual aparentemente não se sentem importunados ao serem filmados, até ignoram a presença da câmara passando por várias vezes a ação filmada. Lembramos que os Bororo ainda se mantinham em amplas atividades produtivas e culturais de suas origens étnicas e com pouco contato com a "civilização". Assim, a presença de um grande número de estrangeiros portando equipamentos diferentes dos que eles conheciam poderia criar um clima de inquietação e de curiosidade, o que não acontece.
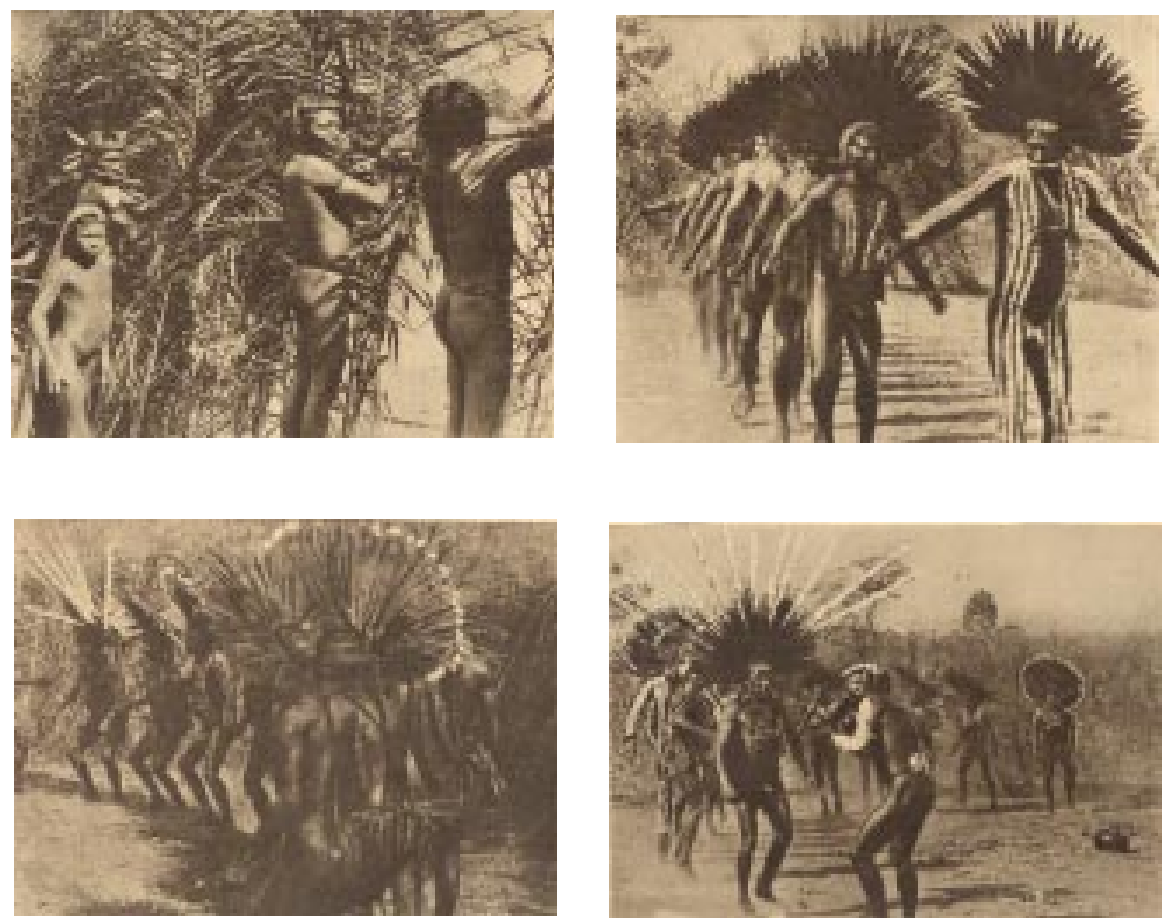
A diferença de postura da câmara nos dois momentos do filme mostra uma preocupação claramente conceitual na metodologia de trabalho de campo com o registro cinematográfico de manifestações culturais. Se no primeiro instante a câmara dirige a cena, no segundo instante a câmara é dirigida pela ação, ou seja, ela busca a gestualidade da dança onde ela aconteça, seja na área central da aldeia, seja fora da aldeia. A dimensão antropológica do tempo, no processo ritualístico, é marca caracterizada signicamente e presença de transitoriedade das etapas que evoluem para a liberação da alma do morto. Entretanto, o registro temporal se dá na narrativa fílmica como recurso de uma lógica de montagem. Nesse sentido, Reis tenta superar as limitações do filme documentário não sonoro, anunciando visualmente ao final de algumas seqüências antes de anunciar nas cartelas 0 assunto a ser tratado na seqüência que virá em seguida. Por meio deste recurso de montagem, 0 filme ganha uma agilidade não explorada nos filmes documentários da época. Assim, a dimensão do tempo ganha sentido na narrativa fílmica e não na importância antropológica do evento.
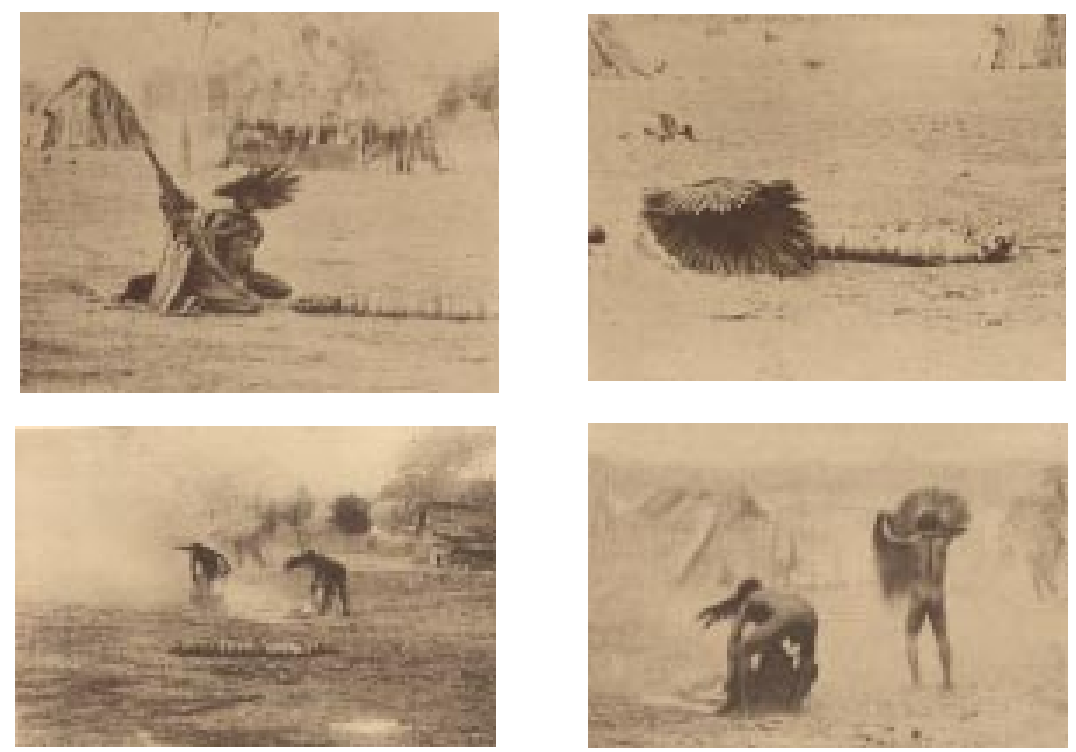

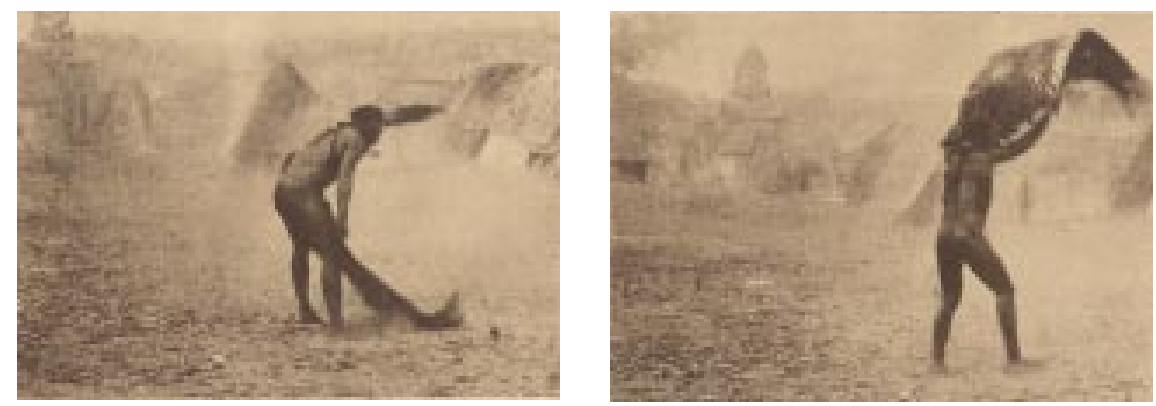

O término do filme no sepultamento primário, sem indicação etnográfica, sugere-nos o fim do funeral, o que não corresponde ao tempo do processo do ritual, já que após haverá uma continuação com novos ritos e um sepultamento definitivo. Entretanto, se Reis não indica no filme que o funeral continua com desdobramentos temporais, ao menos em cartelas, pois sabemos das dificuldades de filmar um ritual apresentando essa dimensão, ele mostra conhecimento dos processos rituais que observou, pois afirma nas legendas publicadas o fato de as últimas cenas do filme serem de um sepultamento temporário e também de os Bororo desenterrarem todos os dias o morto e molhá-lo para acelerar a decomposição dos tecidos (Rondon, 1946: 278). E reafirma suas observações em outro texto colocando as limitações de seu equipamento:

Assim o facto que apreciei de um cadaver de mulher, que, enterrada perto do Bahyto, era desenterrrada todas as manhãs para ser molhada, e no oitavo dia levada para uma lagôa distante, onde a desencarnavam quatro índios, até que os ossos, depois de lavados, ficassem bem brancos, era um quadro de arrepiar os cabellos; não tomei por muitas razões e a mais forte é que elles fazem tudo isto antes da luz do dia, conforme avontade de Boppe (divindade). Só talvez o Coronel Rondon poderia transferir a hora dessa cerimonia: nós nada obtivemos. (Magalhães, 1942: 325)

Essa passagem reafirma a liderança que Rondon incorporava em seus comandados pois lhe é atribuída uma força que até mesmo extrapola seus comandados e lhe atribui poderes que podem mudar etapas do processo do ritual funerário. Em outra passagem vemos que Reis ainda 
Revista de Antropologia, São Paulo, USP, 2002, v. 45 noํ 1.

tentou fazer mudanças que possibilitassem a filmagem, diz ele se referindo ao momento intenso das escarificações:

Como quadro de sensação este seria primoroso; lamentavelmente, sendo tudo isso praticado dentro deuma choupana, muito escura, eo filmenecessitando para a sua bôa impressão de uma certa velocidade instantanea (ao menos de 1/ 30 de segundo) era absolutamente impossivel poder obte-lo naquellas condições, a menos que se devesse descobrir o alojamento; contra isso se oppoz o chefe Manetore, que era o dono da cerimonia, por pertencer a moça defuntaá divisão differente da sua, conforme a lei borôro; elle dizia que isto desagradaria á familia da morta e elle, sendo encarregado dos funerais não queria motivos de censura. (Magalhães, 1942: 326)

Continuando, Reis reafirma suas limitações na realização do filme e das etapas do processo ritualístico e acrescenta novamente a crença em uma interferência de Rondon que possibilitasse realizar as cenas com pouca luz em outras condições favoráveis, as quais tornariam muito mais completo o filme. Ele tinha consciência da sua importância:

Assim pude somente tomar os quadros ao ar livre, mas não se diga que a vista destes nos fará conhecer a vida e costumes dos índios "Coroados", porque muito mais interessantes e bonitos são os quadros do interior de suas casas. Q uando se puder completar este film com os assumptos que faltam, então elle sobrepujará outro qualquer, e para isto dependerá somente dos bons officios do Chefe da Commissão, unico talvez que poderá obter delles todas as facilidades. (Idem)

O equipamento cinematográfico da Secção de Photographia e de Cinematographia da Comissão Rondon, criada em 1912 e oficializada em 1914, sob a chefia do então Tenente Thomaz Reis, tinha à sua disposição uma câmara Williamson, de 30 metros, e uma D ebrie Studio, de 120 metros. 0 investimento em cinema por parte da Comissão dotou-a de modernos procedimentos para a época. Amílcar A. Botelho de Magalhães, chefe do escritónio central da Comissão, assim se refere à Seção:

Todos os processos mais modernos da cinematographia eram alli applicados, e a Comissão Rondon dispunha então de todas as machinas necessárias para a organização completa dos seus filmes, inclusive a impressão 
dos positivos e dos letreiros, a secagem artificial, o enrolamento mecanico das bobinas, etc., tudo movido a electricidade. 0 próprio C apitão R eis dirigiu toda a installação, com a mais notavel proficiencia, e tudo funccionava as mil maravilhas até eu deixar o Escriptorio Central, em maio de 1922. (Magalhães, 1930: 342)

O Major Thomaz Reis também desenvolveu um sistema artesanal de revelação de filmes em plena selva. A destreza operacional do Major Reis se nota também na captação das imagens em campo. D urante a decupagem pudemos observar que 0 encadeamento das seqüências, em alguns momentos, pressupunham uma cognição do produto final. Em várias passagens, a montagem aparece quase como uma edição de gatilho, tal a velocidade de mudança de ângulo da câmara em seu próprio eixo, ou seja, no tripé, para dar continuidade ao registro dos movimentos das danças sem uma "perda" de continuidade. Podemos notar também que a montagem deve ter utilizado grande parte das filmagens de campo, ou seja, aparentemente o material é quase bruto, reforçando assim, 0 fotógrafo Thomaz Reis. Assim, o fato de todas as tomadas terem sido feitas ao ar livre, com luz natural, e excluídas as importantes cenas que ocorriam dentro das casas, foi uma frustração para Reis que fez um impressionante relato de suas dificuldades, no qual mostra sensibilidade etnográfica e plena consciência das limitações de seu filme:

Assim o fato que apreciei de um cadáver de mulher, que, enterrado perto do Baíto, era desenterrado tôdas as manhãs para ser molhado, eno oitavo dia levado para uma lagoa distante, onde o descarnavam quatro índios, até que os ossos, depois de lavados, ficassem bem brancos, era um quadro de arrepiar os cabelos; não tomei um filme por muitas razões e a mais forte é que êles fazem tudo isto antes da luz do dia, conforme a vontade de Bôpe (... ). $Q$ uando morreu essa mulher, todos os parentes vieram junto à defunta, que estava inteiramente untada de Nonôgo (urucum), e sôbre ela deixaram correr o sangue que jorrava de centenas de talhos e arranhões feitos sôbre si mesmas com umas conchas afiadas (... ). Enquanto essas mulheres se maltratavam dêste modo, a defunta jazia sob um banho de sangue que lhe era oferecido, com última relíquia, por suas amigas; ao redor o Bacorôro especial do funeral, sustentado por todos os Boemejêras, êstes untados de encarnado e agitando os Bápus compassadamente, trovejava - pode-se dizer, comparando bem, pelo ruído de seus passos pesados e ritmo gutural de seu canto, ea zoada de 
Revista de Antropologia, São Paulo, USP, 2002, v. 45 noํ 1.

chocalhos nessa hora sacudidos com tôda a impetuosidade. 0 pó asfixiava, as mulheres bradavam as boas qualidades da defunta, outras se cortavam em prantos; sangue e lágrimas misturavam-se; o solo estremecia sob os pés dos chefes Borôro com o "Parico", que dava àqueles vultos vermelhos e suarentos, de rostos contraídos pela febre dessas doenças, a impressão infernal e assustadora de oriundos de uma visão apocalíptica. (Rondon, 1953a: 224)

A esta impressionante observação e à falta de condições das tomadas cinematográfica por falta de luz, Reis acrescenta sua sensibilidade ao produto que está realizando ao sugerir a idéia de exótico e de força emocional que tais cenas poderiam causar nos espectadores:

Ha entre elles praticas innocentes e outras verdadeiramente horriveis; ora, em cinematografia, uma arte que, como todas as outras, passa por tantas modalidades, quanto mais de perto tem que acompanhar as inclinações e gostos do publico, o que é horrivel é que agrada; tanto mais barbara é uma scena tanto melhor para tonificar os nervos gastos das nossas plateias, avidas do sensacional. (Magalhães, 1942: 325)

As únicas imagens internas de casas indígenas com cenas cotidianas foram feitas pelo próprio Reis entre os índios Arití e publicadas no volume I entre as páginas 83 e 115, juntamente com imagens do fotógrafo José Louro, constituindo um dos poucos blocos fotográficos sem fotogramas cinematográficos e de excelente qualidade técnica e estética. Cabe ainda colocar nessa análise do filme Rituaes e festas Bororo o fato de apenas poucas imagens fotográficas terem sido publicadas junto aos fotogramas cinematográficos e também realizadas por Reis, confirmando sua prioridade de documentar em cinema (Rondon, 1953a: 227-97). Entretanto, pelo fato de não ter uma qualidade técnica que permitisse uma boa reprodução gráfica, notaremos nessa seqüência uma interferência nas imagens cinematográficas com retoques feitos para acentuar expressões, vestimentas e objetos. 0 retoque na imagem aparecerá muitas vezes nas imagens reproduzidas no livro, sempre que a qualidade técnica foi prejudicada por falta de luminosidade ou de um erro de tomada, algumas vezes de uma forma grosseira. A seqüência publicada termina com uma distribuição de brindes em uma outra aldeia Bororo, em posto do SPI ("antiga povoação de São Lourenço"), também 
em fotografias de Reis e, em uma das fotografias, vemos índios Bororo trabalhando na construção das linhas telegráficas. 0 ponto mais intrigante da relação fílmica com a publicação do livro Índios do Brasil é verificarmos que, como já disse, uma parte inicial não aproveitada no filme consta da publicação como fotogramas cinematográficos de Reis. Essa parte inicial mostra um grupo de índios Bororo vestidos, na verdade fardados com roupas doadas pelos militares. A pergunta é: por que Reis não optou por usar essas imagens mostrando um índio "vestido" e "pacificado"? Ao escolher a temática "rituais e festas", ele naturalmente omitiu essa presença de elementos aculturados entre os Bororo, ou seja, a intencionalidade de mostrar um "bom selvagem" fica caracterizada nessa omissão cinematográfica e explícita na publicação 36 anos depois, quando ele já tinha inclusive falecido. O utra diferença acontece na ordem de apresentação dos fotogramas já na parte final do filme: enquanto no filme as últimas cenas são do sepultamento primário, no livro os últimos fotogramas publicados remetem para a continuação do ritual.

A última festa fúnebre é o "Aidje" em que todos, pintados de formas diferentes, se dirigem para um mato próximo. Ali pintam de barro amarelo os quatro índios que devem desencarnar o defunto. (Rondon, 1946: 287)
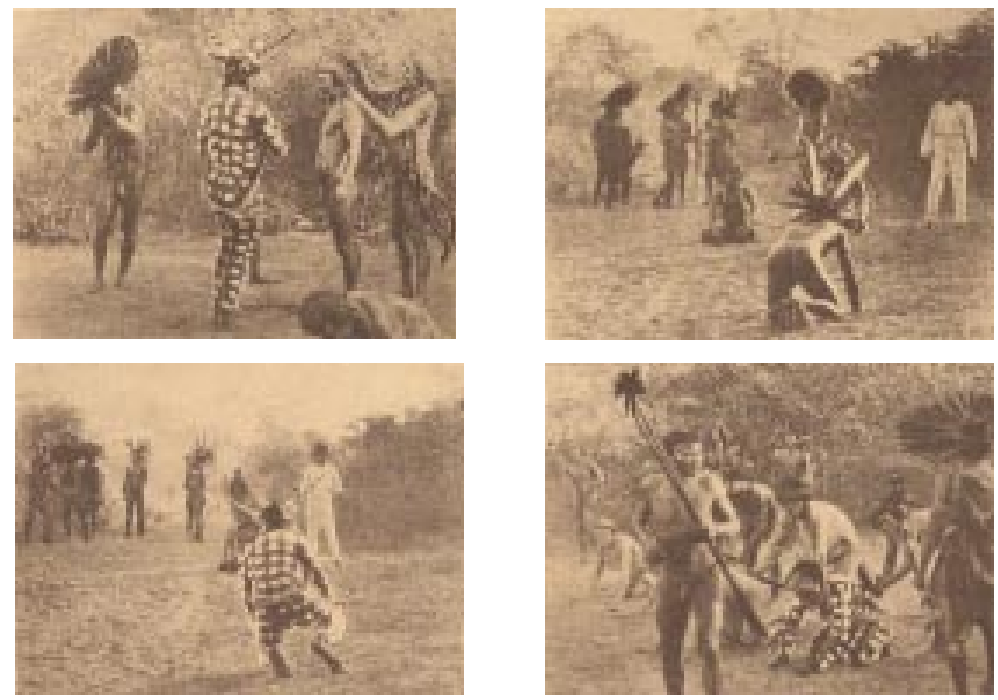
A narrativa publicada no livro termina bruscamente, diferentemente da "finalização" cinematográfica. Como podemos ver, Reis inverte a ordem cronológica das tomadas na edição do filme para criar um encerramento com alguma dramaticidade, mesmo que essa inversão descaracterize a ordem temporal e "linear" do ritual, pois as cenas de preparação para o desencarnamento do morto acontecem antes do sepultamento primário no filme. Não há aqui uma crítica a essa inversão como estratégia de edição mas somente a constatação de que Reis omite esse dado etnográfico que ele conhecia muito bem, como vimos em passagens acima citadas, mostrando também que ele conhecia a narrativa cinematográfica, ou seja, ele não fez a edição ingenuamente.
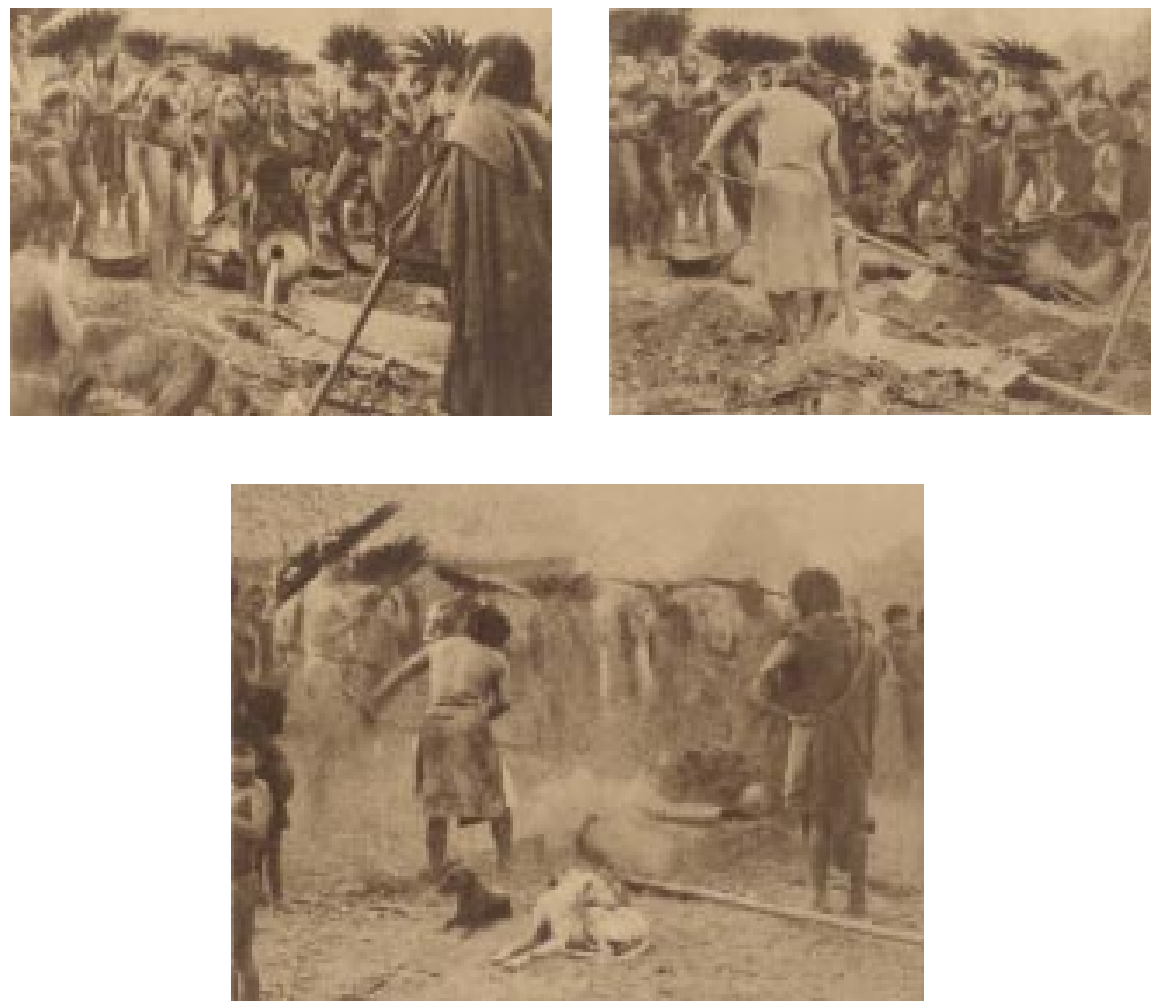
A construção de uma imagem do índio como um "selvagem" na imagética rondoniana é afirmada na relação de indicialidade ou na qualidade sígnica de existência por contigüidade física impressa na última cartela do filme que diz: "Tínhamos ali a sensação dos remotos tempos do D escobrimento". 0 "selvagem" poderia ser então identificado como um mito de origem da brasilidade.

0 que fica claro nessa aproximação dos filmes do Major Thomaz Reis é a presença de elementos que nos permitem apontar para uma metodologia de captação das imagens em campo e uma proposta de montagem cinematográfica. A compreensão das intencionalidades imagéticas no discurso fílmico e nas fotografias da Comissão Rondon permite-nos aprofundar relações ideológicas ainda não estudadas do período inicial do SPI. Uma segunda aproximação necessária à compreensão completa do filme poderá ser feita nas informações propriamente etnográficas do funeral Bororo, que não é objetivo desse estudo e deverá ser feita por um especialista na etnologia Bororo. 0 filme Rituaes e festas Bororo, que já é considerado um dos primeiros filmes etnográficos do mundo ${ }^{12}$, é mais do que simples pioneirismo na produção de filmes sobre povos "exóticos", pois contém características de metodologias de campo desenvolvidas posteriormente pela antropologia.

\section{Notas}

1 É também fotógrafo.

2 Esther de Viveiros, no livro Rondon onta sua vida, utiliza diários, relatórios e textos do próprio Rondon para escrever uma autobiografia caracterizada como uma "hagiografia positivista" por Antonio Carlos de Souza Lima (1990: 18). Souza Lima apresenta em anexo ao artigo uma ampla bibliografia biográfica sobre Rondon e também sua trajetória familiar e profissional.

30 material imagético da Comissão Rondon está principalmente sob a custódia do Museu do Índio (RJ), os oniginais em película cinematográfica estão depositados 
na Cinemateca Brasileira (SP). Existem álbuns efotos esparsas em outros museus, como o Museu Histórico Nacional (RJ), o Museu dos Correios e Telégrafos (Brasília), o Museu de Arqueologia eE tnologia (SP). Foram encontrados álbuns também no Musée de L' Homme, em Paris. Esses dados confirmam a estratégia de Rondon de divulgar os resultados de suas campanhas através da imagem para variados públicos e, assim, os álbuns reproduzidos tiveram vários destinos. Mas a maior parte dos originais fotográficos, inclusive chapas de vidro, são mantidos no Museu do Índio.

4 É importante citar o Sr. Lamonica que trabalhou com Rondon e foi uma espécie de "guardião" dos originais fotográficos no Museu do Índio.

5 A decupagem não é apresentada aqui mas pode ser encontrada na minha tese de doutorado (Tacca, 1996a).

6 Não pretendo fazer uma comparação ou uma análise das diferentes documentações sobre o funeral Bororo, mas acredito que minha análise possa contribuir com 0 pesquisador que porventura vier a estudar a farta documentação fotográfica e cinematográfica existente sobre 0 assunto. Existem dois filmes feitos respectivamente por Haenz Foerthman (1956) e D ina Lévi-Strauss (1934), a excelente documentação fotográfica feita por Foerthman no início da década de $1940 \mathrm{em}$ médio formato, e as documentações recentes, entre elas as documentações fotográficas de Kim-Ir-Sen e da própria Sylvia C. Novaes.

7 Um estudo da formação de identidades entre os índios brasileiros e especificamente entre os Bororo.

8 Relatório do Coronel Amilcar A. Botelho de Magalhães, secretário do Conselho Nacional de Proteção ao Índio, publicado inicialmente na revista A mérica Indígena (1943: 154).

9 O s cinco mandamentos de Andrada e Silva citados por Rondon:

"1. justiça não esbulhando mais os Índios, pela força, das terras que ainda lhes restam, e de que são legítimos senhores;

2. brandura, constância e sofrimento de nossa parte, que nos cumpre, como a usupardores e cristãos; 
3. abrir comércio com os bárbaros, ainda que seja com perda da nossa parte;

4. procurar com dádivas e admoestações fazer pazes com os índios inimigos;

5. favorecer por todos os meios possíveis os matrimônios entre índios e brancos e mulatos" (Rondon, 1942: 35).

10 Nas atribuições que o próprio Roosevelt descreve como atividades dos participantes da expedição, como a zoologia, geografia, geologia, astronomia, comunicação, transporte e serviços médicos, resta-lhe somente o "trabalho" de coleta de espécimes através da caça, que ele mesmo se incumbia de fazê-lo (Roosevelt, 1942: 172).

11 Esta fotografia também é publicada por Rondon no primeiro volume do livro Índios do Brasil eécreditada como "foto Dr. Kermit Roosevelt" (Rondon, 1946: $67)$.

120 filme foi apresentado na mostra Premier contact, premier regard, organizada por Pierre Jordan, em 1992, na cidade de Marseille, e a foto da capa do catálogo é um fotograma do filme de Reis.

\section{Bibliografia}

DUBOIS, P.

$1998 \quad 0$ ato fotográfico e outros ensaios, Campinas, Papirus.

FLUSSER, V.

1985 Filosofia da caix a preta - ensaios para uma futura filosofia da fotografia, São Paulo, Hucitec.

GUSMÃO, C.DE

1942 Rondon, Rio de Janeiro, Livraria José Olympio.

JORDAN, P.

1992 Premier contact - premier regard, Marseille, Musée de Marseille/ Images en Manluvres Editions. 
MAGALHÃES, A.B. DE

1930 Pelos sertões do Brasil, 1.ed., Rio de Janeiro, Globo.

1942 Impressões da C omissão Rondon, 5.ed., Rio de janeiro, Companhia Editora Nacional.

1943 “O problema de civilização dosíndios no Brasil”, A méric Indígena, México, D.F, vol. III(2).

NOVAES, S. C.

1993 Jogo de espelhos, São Paulo, Edusp.

REIS, L. T.

1945 Serviços fotográficos e cinematográficos e Serviço antropométrico, in E x pedição ao Rio Ronuro (1924), Rio de Janeiro, Ministério da Agricultura/ CNPI/ Imprensa Nacional.

RONDON, C.M.DAS.

1920 Relatório dos trabalhos realizados de 1900-1906, Rio de Janeiro, D epartamento de Imprensa Nacional. Commissão de Linhas Telegraphicas do Estado de Minas Gerais ao Amazonas.

1922 Conferências - realizadas em 1910 no Rio de Janeiro eem S. Paulo, Rio de janeiro, Typographia Leuzinger, n. 68. Commissão de Linhas Telegraphicas Estratégicas de Matto-G rosso ao Amazonas.

1943 "Problema indígena", A merica Indigena, Mexico, vol. III(1).

1946 Índios do Brasil do C entro ao N oroeste e Sul de Mato-G rosso, Rio de janeiro, Ministério da Agricultura/ CNPI, n. 97, vol. I.

1953a Índios do Brasil - Cabeceiras do X ingu/ Rio A raguaia e0 iapóque, Rio de janeiro, Ministério da Agricultura/ CNPI, n. 98, vol. II.

1953b Índios do Brasil - N orte do Rio A mazonas, Rio de Janeiro, Ministério da Agricultura/ CNPI, n. 99, vol. III.

ROOSEVELT, T.

$1942 \quad$ N as selvas do Brasil, Rio de Janeiro, Ministério da Agricultura. 
SEM AUTOR

1916 M issão Rondon - apontamentos realizados pela Commissão de L inhas T elegraphicas E stratécicas de Matto-G rosso ao A mazonas de 1907 a 1915, Rio de Janeiro, Typographia do Jornal do Commencio.

SOUZA LIMA, A. C.

1990 Santo soldado, Rio de Janeiro, Museu Nacional, Comunicação 21.

1992a "Governo dos índios sob a Gestão do SPI", H istória dos índios no Brasil, São Paulo, Companhia das Letras/ Secretaria Municipal deCultura/ Fapesp.

1992b Um grande cerco depaz - poder tutelar e indianidadeno Brasil, Petrópolis, Vozes, 1995.

1995 "Festas e rituaes Bororo", C adernos de A ntropologia eImagem, UERJ, n. 1.

TACCA, F. DE

1996 “A imagética da Comissão Rondon e do SPI", Journal of O sak a U niversity of F oreign Studies, O saka, New Series 16.

1997 "O pioneirismo de Thomas Reis", A nais da II Reunião de A ntropologia do Mercosul, Uruguai.

1998 "O índio pacificado: uma construção imagética da Comissão Rondon", Cadernos de A ntropologia eImagem, Rio de Janeiro, NAI, Programa de Pós Graduação em Ciências Sociais/ UERJ.

1999a O feitipo abstrato: do etnográfico ao estratégico. A imagética da Comissão Rondon, São Paulo, pp. 385, tese, USP.

1999b “O feitiço abstrato", Cademos da Pós-G raduação, Instituto de Artes, Unicamp, n. 2.

VIVEIROSDE CASTRO, E.

1958 Rondon conta sua vida, Rio de Janeiro, Livraria São José. 
ABSTRACT: This article investigate the film Rituaes e festas Bororo (1917), produced by Luiz Thomaz Reis, during his first film-version. He created the Photographic and Cinema D epartment of Rondon Commission in 1912 being its principal filmmaker and photographer. The analysis focus the cinema narrative and overlap it with another photograms published like a photographic narrative in Índios do Brasil (1946) by Rondon. This film together with another similar images of Rondon Commission build a "selvage" sign for Brazilian Indians image. Today its is considered not only a pioneer film but one of the most important documents in ethnographic film history.

KEY-WO RD S: photography, ethnography film, anthropology, Bororo, Luiz Thomaz Reis. 